\section{A integração dos aspectos sintáticos, semânticos e pragmático- discursivos na manifestação da evidencialidade}

The integration of syntactic, semantic and pragmaticdiscursive aspects in the manifestation of evidentiality

Cláudia Ramos CARIOCA (Unilab) claudiacarioca@unilab.edu.br

Recebido em: 29 de mar de 2018. Aceito em: 04 de jun. de 2018.
CARIOCA, Cláudia Ramos. A

integração dos aspectos sintáticos, semânticos e pragmático-discursivos na manifestação da evidencialidade. Entrepalavras, Fortaleza, v. 8, n. esp. p. $112-129$, set. 2018 .

Resumo: Este artigo apresenta reflexões sobre a integração dos aspectos sintáticos, semânticos e pragmático-discursivos na manifestação da evidencialidade, em dados levantados durante a Tese de Doutoramento (CARIOCA, 2011) intitulada "A Evidencialidade em textos acadêmicos de grau do português brasileiro contemporâneo". A análise, orientada por pressupostos funcionalistas, conta com uma dimensão teórica, voltada para a rediscussão do limite conceitual da categoria linguística evidencialidade; e uma dimensão analítica, que, em constante diálogo com a teoria, investiga, qualitativa e quantitativamente, o uso de marcas da evidencialidade nas monografias, dissertações e teses. Constatou-se que, pela integração dos aspectos sintáticos, semânticos e pragmático-discursivos, os efeitos de sentido associados ao uso de meios de expressão da evidencialidade na construção da argumentação dos textos acadêmicos de grau do português brasileiro contemporâneo colaboram para que a atenuação da responsabilidade seja feita de forma discreta, sinalizando que algo não está sendo dito de forma categórica.

Palavras-chave: Evidencialidade.

Funcionalismo. de grau. Português brasileiro contemporâneo. 
Abstract: This article presents reflections on the integration of syntactic, semantic and pragmatic-discursive aspects in the manifestation of evidentiality, in data collected during the Doctoral Thesis (CARIOCA, 2011) entitled "The Evidentiality in academic texts of contemporary Brazilian Portuguese degree". The analysis, guided by functionalist assumptions, has a theoretical dimension, focused on the re-discussion of the conceptual boundaries between the modality and evidentiality categories; and an analytical dimension that, in constant dialogue with theory, investigates, qualitatively and quantitatively, the use of evidentiality marks in monographs, dissertations and theses. It was verified that, through the integration of the syntactic, semantic and pragmatic-discursive aspects, the effects of sense associated to the use of means of expression of evidentiality in the construction of the argumentation of the academic texts of degree of contemporary Brazilian Portuguese collaborate so that the attenuation of responsibility is done in a discreet way, signaling that something is not being said categorically.

Keywords: Evidentiality. Functionalism. Academic texts of degree. Contemporary Brazilian Portuguese.

\section{Considerações iniciais}

A maneira como o ser humano se comunica é extremamente reveladora de suas intenções. A informação comunicada por alguém pode ter como fonte o próprio sujeito-enunciador ou outras fontes por ele implicadas por meio de marcas contidas no enunciado.

Ao manifestar essas marcas de indicação da fonte do que é asseverado, o sujeito-enunciador recorre à utilização do que denominamos de evidencialidade. Nessa manifestação, podem ser depreendidas as atitudes em relação à informação que ele transmite ou o conhecimento que possui acerca dela. Ou seja, a evidencialidade é uma categoria linguística que permite, estrategicamente, a manipulação de informações quanto à explicitação da fonte do conhecimento informado e ao grau de comprometimento do sujeito-enunciador com tais informações.

Assumimos, com Bakhtin (1997, p.279), que a utilização da língua, em várias esferas da atividade humana, efetiva-se por meio de enunciados orais ou escritos, concretos e únicos, que refletem as condições específicas e as finalidades de cada uma dessas esferas, de forma indissolúvel, pelo conteúdo (temático), pelo estilo verbal (isto é, pela seleção operada nos recursos da língua) e pela construção composicional.

Uma teoria de base para a pesquisa ora empreendida só poderia situar-se de forma a considerar o contexto situacional no qual se concretiza o ato do desenvolvimento da escrita do texto, pois, dependendo da finalidade que se propõe o falante é que se efetiva o ato ilocucionário mediante o uso dos mais variados recursos linguísticos para sua operacionalização. 
v. 8 (esp.)

$112-129$ set. 2018

A pesquisa que aqui propomos assume a concepção sociointeracional de linguagem - já que, na construção do discurso acadêmico, o falante prevê a interação com o ouvinte deixando pistas - e, com o objetivo de interpretar melhor as opções linguísticas na manifestação da evidencialidade, adota uma perspectiva funcionalista ao reconhecer que tais opções encontram-se estreitamente condicionadas pelos propósitos comunicativos do falante e/ou do gênero em questão.

A discussão sobre os aspectos funcionais no estudo da linguagem já vem ocorrendo há bastante tempo, por isso algumas premissas já estão postuladas como lições básicas de uma gramática de direção funcional. Essas premissas Neves (2006, p. 16) expõe assim:

- A linguagem não é um fenômeno isolado, mas, pelo contrário, serve a uma variedade de propósitos (Prideaux, 1987).

- A língua (e a gramática) não pode ser descrita nem explicitada como um sistema autônomo (Givón, 1995).

- As formas da língua são meios para um fim, não um fim em si mesmas (Halliday, 1985).

- Na gramática estão integrados os componentes sintático, semântico e pragmático (Dik, 1978, 1980, 1989a, 1997; Givón, 1984; Hengeveld, 1997).

- A gramática inclui o embasamento cognitivo das unidades linguísticas no conhecimento que a comunidade tem a respeito da organização dos eventos e de seus participantes (Beaugrande, 1993).

- Existeuma relação não-arbitrária entrea instrumentalidade do uso da língua (o funcional) e a sistematicidade da estrutura da língua (o gramatical) (Mackenzie, 1992).

- O falante procede a escolhas, e a gramática organiza as opções em alguns conjuntos dentro dos quais o falante faz seleções simultâneas (Halliday, 1973, 1985).

- A gramática é susceptível às pressões do uso (Du Bois, 1993), ou seja, às determinações do discurso (Givón, 1979b), visto o discurso como a rede total de eventos comunicativos relevantes (Beaugrande, 1993).

- A gramática resolve-se no equilíbrio entre forças internas e forças externas ao sistema (Du Bois, 1985).

- O objeto da gramática funcional é a competência comunicativa (Martinet, 1994). 
Tais noções advém da base dos estudos da Escola Linguística de Praga iniciados na segunda década do Século XX e se projetam em diversificadas correntes funcionalistas, como é o caso do funcionalismo inglês, do funcionalismo norte-americano e do funcionalismo holandês.

Segundo Nogueira (2006, p. 2), o funcionalismo praguense caracteriza-se pela consideração das funções dos meios linguísticos, tendo em vista as necessidades de comunicação e expressão dos indivíduos, pelas propostas classificatórias das funções da linguagem (Bühler e Jakobson), e pelas noções de perspectiva funcional da sentença (Mathesius) e de dinamismo comunicativo (Firbas).

Sobre o funcionalismo inglês, Nogueira (2006, p. 3) explicita que a proposta de Halliday é:

De uma teoria sistêmico-funcional do significado como escolha, por meio da qual a língua, como qualquer outro sistema semiótico, é interpretada como redes de opções engrenadas. Por meio de uma gramática dessa natureza, a análise linguística revela por que um texto significa o que significa e avalia se ele atinge efetivamente, ou não, os seus propósitos.

Nesseenfoque, Halliday (1985) estipula um sistema fundamentado em três funções básicas: a função ideacional, a função interpessoal e a função textual.

Acerca do funcionalismo norte-americano, vale ressaltar as pesquisas de Hopper e Thompson (1980) acerca da transitividade e do relevo discursivo, como também de Du Bois (1987) sobre a base discursiva da ergatividade, estabelecendo a hipótese da estrutura argumental preferida que toma como parâmetro o fluxo da informação. Os estudos de Talmy Givón se configuram como contrários aos parâmetros formalistas, reveladores de várias diretrizes pragmáticas que afirmam a motivação funcional das estruturas gramaticais (NOGUEIRA, 2006, p. 4).

Givón (2001) postula o reconhecimento da gramática como um instrumento discretizante, categorizador por excelência, mas sem deixar de perceber as exceções de uma regra, por defender que a flexibilidade residual, a gradualidade e a variabilidade são utilizadas na adaptação conforme a motivação linguística. Marcação e Iconicidade são dois conceitos proeminentes nos estudos givonianos, os quais permitiram a defesa de alguns princípios da organização gramatical icônica como regras de uma protogramática. A saber: regras de entonação (ênfase e previsibilidade, melodia e relevância, pausa e ritmo), regras de espaçamento (proximidade e relevância, proximidade e escopo), regras 
v. 8 (esp.)

$112-129$

set.

2018

de sequência (ordem e importância, ordem de ocorrência e ordem reportada), regras de quantidade (expressão zero e previsibilidade, expressão zero e relevância) ${ }^{1}$.

Quanto ao funcionalismo holandês, também referido em Nogueira (2006), destaca-se a proposta de uma teoria funcional da gramática de Simon Dik (1989), formulando que a interação verbal ocorre por meio das expressões linguísticas: entidades estruturadas, governadas por regras (semânticas, sintáticas, morfológicas e fonológicas) e princípios pragmáticos que determinam sua formulação, bem como sua utilização. Por esse motivo a Gramática Funcional propõe a integração dos componentes de análise e coloca a pragmática como aquele que garante que as regras de uma determinada língua sejam explicitadas de acordo com a sua funcionalidade.

\section{A Evidencialidade como categoria linguística}

Historicamente, o termo evidencialidade aparece na primeira metade do Século XX a partir dos trabalhos de Boas e Sapir, segundo esclarecem Dendale e Tasmowski (2001). Somente veio a ser considerado em trabalhos linguísticos algumas décadas depois com a pesquisa Shifters, verbal categories, and the Russian verb, na qual Jakobson (1957) tomou como escopo as línguas Balcânicas, Eslavas e Românicas.

A década de 1980 marca o reconhecimento da evidencialidade como tema relevante na pesquisa envolvendo as línguas em seu aspecto semântico-pragmático. Com a publicação de Chafe e Nichols (1986), Evidentiality: the linguistic coding of epistemology, onde se encontram reunidos todos os trabalhos apresentados na primeira conferência sobre o tema, realizada em Berkeley (EUA), em 1981, a evidencialidade passa a ter enorme significado no âmbito linguístico.

A partir de então, eventos internacionais marcam a divulgação dos trabalhos sobre a evidencialidade, como é o caso do Colóquio Internacional de Pragmática, em 1998, com uma série de debates intitulada Débat's sur l'Evidentielité, organizada por Patrick Dendale e Liliane Tasmowski na Université d'Anvers (UA).

A evidencialidade chama a atenção por ser considerada como meio de revelação da fonte de um conteúdo proposicional, marcando também o grau de comprometimento do falante com a verdade da

${ }^{1}$ A relação destes conceitos com evidencialidade pode ser verificada na tese completa disponível em http://www.repositorio.ufc.br/handle/riufc/3608. 
proposição (BYBEE e FLEISCHMANN, 1995, p.4), manifestando-se, principalmente, através de operadores evidenciais (WILLET, 1988; BOTNE, 1997; FLOYD, 1999).

O estudo de Nuyts (1993, p. 946) conclui ser toda qualificação modalbaseadanecessariamente em uma evidência, podendovariarapenas a qualidade da evidência que se tem, mas, certamente, sem evidência, nenhuma avaliação de um estado-de-coisas é possível, podendo alguém simplesmente optar por dizer que não sabe, acrescentando ainda que "a evidencialidade pode se constituir propriedade definitória da modalidade epistêmica" (NUYTS, 2001, p.947), mediante a justificativa de que todo dito é gerado de uma fonte que não necessariamente é o falante.

Considerando a relação entre modalidade e evidencialidade, no que diz respeito à forma como o falante se comporta, Hengeveld (1989, p. 138), já propondo uma tipologia, apresenta uma diferenciação entre a modalidade epistemológica subjetiva e a modalidade epistemológica evidencial:

O que esses dois tipos têm em comum é a relevância da fonte da informação contida na proposição. No caso dos evidenciais, essa fonte é caracterizada como diferente do falante. No caso da modalidade subjetiva, o falante é a fonte ${ }^{2}$.

Dall'Aglio Hattnher et al (2001) tentam equacionar as duas categorias apresentando uma proposta de classificação que considera a fonte de informação individualizada e a fonte de informação compartilhada, pois o falante, segundo as suas intenções comunicativas, pode optar por explicitar ou não outras fontes de informações que veicula. Para isso, toma por base os apontamentos de Hoff (1986, apud Dendale e Tasmowski, 1994, p.2), conforme a seguir:

Os evidenciais ou os 'meios de justificação' indicam que tipo de evidência está disponível para assegurar a confiabilidade do enunciado no qual eles estão inseridos. Assim, se o falante escolhe indicar a fonte do saber que seu enunciado transmite, ele oferece a seu interlocutor a possibilidade de avaliar por si próprio a confiabilidade dessa informação. A avaliação da verdade de uma proposição será feita, então, com diferentes graus de adesão do falante, segundo as diferentes fontes de informação apresentadas, que podem ser um relato de terceiros, uma percepção visual ou auditiva, uma inferência ou suposição do próprio falante.

\footnotetext{
${ }^{2}$ What both subtypes have in common is the relevance of the source of the information contained in a proposition. In the case of evidential this source is characterized as different from the speakes. In the case of subjective modality the speaker is the source.
} 
v. 8 (esp.)

$112-129$

set.

2018
O falante também pode optar por não indicar o tipo de evidência de que dispõe, se o conhecimento subjacente à sua avaliação for do domínio comum ou, principalmente, se ele quiser fazer parecer que é um conhecimento partilhado (DALL'AGLIO HATTNHER et al., 2001, pp. 116-117).

Os trabalhos de Anderson (1986), de Willet (1988) e de Givón (2001) proporcionaram uma abertura significativa para a descrição da evidencialidade como categoria gramatical e auxiliaram Galvão (2001) na proposta de uma tipologia evidencial ampliada para especificar a geração de diferentes experiências a partir de uma mesma ação cognitiva, tudo dependendo "do quão envolvido esteja o usuário da língua no processamento da origem, da fonte do conhecimento veiculado" (p. 97). Delimita ainda que há um tipo e um grau de envolvimento do usuário da língua com a situação descrita, relacionado com o tipo de experiência sensorial ou cognitiva geradora do conteúdo proposicional, além de também explicitar de que forma o ouvinte pode interpretar a experiência cognitiva do falante na situação de interação.

A existência de um sistema evidencial no português é uma proposta sugerida por Galvão (2001), sendo que a pesquisadora dedicouse, particularmente, ao processo de gramaticalização da expressão diz que. Outra pesquisa que vislumbra o surgimento de marcas que especificam a fonte da informação no português é a de Dall'Aglio Hattnher et al (2001), na qual expressões do tipo diz que, parece que, sei lá, não sei podem ser consideradas como estratégias de (des)comprometimento e passam pelo processo de gramaticalização, ou seja, estão deixando de ser itens lexicais plenos para assumirem uma nova função: a de itens evidenciais ou modais.

Em pesquisa anterior, Dall'Aglio Hattnher (1996) já anunciara, embrionariamente, uma gradação do comprometimento do falante em relação à evidencialidade, só que a noção evidencial estava inclusa à modalidade epistêmica como uma instância que revelava, segundo a autora:

\footnotetext{
Uma proposição em sua função interpessoal: o falante se utiliza de meios lingüísticos para expressar sua atitude com relação ao seu ato de fala. Desse modo, [...] ao situar a qualificação epistêmica no nível da proposição, o falante assume, com diferentes graus de adesão, seu enunciado (DALL'AGLIO HATTNHER, 1996, p. 163).
}

Já numa relação direta do grau de comprometimento com a responsabilidade que o falante pode ter com a proposição que emite, Thompson (1996, p. 37) afirma que é possível determinar alguns valores ou 
escalas indicativas para este grau (alto, médio e baixo); tomando por base o estabelecido por Halliday (1994) para os operadores modais, conforme o grau de proximidade, de probabilidade ou certeza conferido à declaração.

As marcas evidenciais servem como estratégias discursivas na construção textual para um maior ou menor comprometimento com a proposição que se quer considerar, portanto, promovem a indicação da fonte do saber expresso pelo falante determinando o grau de tensão que se estabelece entre os interlocutores (KOCH, 1986). Desse modo, saber utilizar essas marcas desenvolve uma relação direta do grau de envolvimento do falante com o que está querendo dizer, fornecendo ao ouvinte subsídios que o farão interpretar corretamente a mensagem proposta como sendo de uma fonte, responsabilizando essa fonte pelo que foi dito.

Vale ressaltar que essa relação entre níveis de comprometimento e evidencialidade foi proposta aqui para a análise dos dados desta pesquisa; então, torna-se oportuna, por hipótese, a tentativa de caracterização de algumas marcas evidenciais, observando a utilização destas como estratégias e classificadas como alto, médio ou baixo comprometimento, as quais se encontram definidas a seguir.

\section{As categorias da análise}

A obtenção dos dados para esta pesquisa concretizou-se a partir da organização de um corpus especializado com 1500 ocorrências de amostras do discurso acadêmico, envolvendo um período de 10 anos que vai de 1998 a 2008, constituído por trabalhos acadêmicos de grau, separados em três gêneros: monografias, dissertações e teses. Supõe-se que esses gêneros textuais apresentam, em grande medida, a explicitação de fontes que não são o próprio autor, o que amplia o quadro de uso das marcas de evidencialidade na relação observável com o grau de comprometimento do produtor textual com a informação veiculada.

Na análise de cada ocorrência, foi observada a manifestação das categorias de análise, as quais foram divididas em três aspectos:

a) Aspectos sintáticos, subdivididos em: a.1) categoria de expressão da evidencialidade (item lexical - verbo, substantivo, adjetivo, advérbio, preposição -, enunciado metalinguístico, justaposição simples e convenções da ABNT); e a.2) posição no enunciado (anteposição, intercalamento, posposição); 
v. 8 (esp.)

$112-129$

set.

2018

b) Aspectos semânticos, subdivididos em: b.1) tipo de fonte da informação (sujeito-enunciador, fonte externa definida e indefinida, domínio comum); b.2) envolvimento com a obtenção do conhecimento (direta, menos direta, indireta); b.3) envolvimento com a transmissão do conhecimento (subjetiva, experiencial, relatada, inferencial);

c) Aspectos pragmático-discursivos (efeitos de alto, médio e baixo comprometimento).

\section{A integração dos aspectos sintáticos, semânticos e pragmático- discursivos na manifestação da evidencialidade}

Baseando-nos na teoria funcionalista da linguagem, paradigma teórico que prega a explicitação e a integração dos componentes da língua na relação com o uso, apresentamos a integração dos aspectos sintáticos, semânticos e pragmático-discursivos para investigar como se manifesta a evidencialidade nos trabalhos acadêmicos de grau do português brasileiro contemporâneo.

Tais aspectos não ocorrem em separado, mas de uma forma integrada, conforme explicitamos nos quadros seguintes.

Ao escrever, o produtor textual não escreve por acaso, mas, dependendo de sua intenção, ou melhor, do efeito de sentido que ele quer ver interpretado pelo leitor, escolhe e organiza estrategicamente a expressão de seu pensamento.

Nos exemplos (01) e (02) abaixo, o produtor textual expressou como dele um pensamento. Ele escolheu comprometer-se de forma integral com o que estava informando (alto comprometimento), pois, do contrário, não teria utilizado as marcas evidenciais que individualizam a fonte da informação como sendo ele, o próprio produtor textual.

Esta proposta de integração dos aspectos sintáticos, semânticos e pragmático-discursivos é observada a seguir: 
Quadro 01 - Análise integrada do uso da evidencialidade para alto comprometimento em D6.F.293

\begin{tabular}{|c|c|c|}
\hline \multicolumn{3}{|c|}{$\begin{array}{l}\text { ANÁLISE INTEGRADA DO USO DA EVIDENCIALIDADE } \\
\text { PARA ALTO COMPROMETIMENTO - OCORRENCIA D6.F.29 }\end{array}$} \\
\hline \multicolumn{3}{|c|}{$\begin{array}{l}\text { (o1) Por isso AFIRMAMOS que a tecnologia imposta ou absorvida à educação } \\
\text { funciona como uma via de acesso e multiplicação das capacidades sensoriais, como } \\
\text { por exemplo, o sentido, a percepção e o estímulo, simples armazenamento de dados, } \\
\text { editoração e etc e dificilmente vamos além deste exercício (p. 36). (D6.F.29) }\end{array}$} \\
\hline ASPECTO & MARCA EVIDENCIAL & ESTRATÉGIA \\
\hline $\begin{array}{l}\text { Pragmático- } \\
\text { discursivo }\end{array}$ & Alto comprometimento & $\begin{array}{l}\text { Sinalizar um pensamento de sua } \\
\text { responsabilidade exclusiva. }\end{array}$ \\
\hline \multirow{3}{*}{ Semântico } & Sujeito-enunciador & $\begin{array}{l}\text { Atribuir a si próprio a fonte da } \\
\text { informação veiculada. }\end{array}$ \\
\hline & Direta & $\begin{array}{l}\text { Atestar que a informação foi obtida } \\
\text { por uma experiência pessoal do } \\
\text { próprio produtor textual. }\end{array}$ \\
\hline & Subjetiva & $\begin{array}{l}\text { Explicitar que a informação é um } \\
\text { conhecimento particular da mente do } \\
\text { produtor textual. }\end{array}$ \\
\hline \multirow[b]{2}{*}{ Sintático } & Intercalada & $\begin{array}{l}\text { Posicionar o evidencial entre a fonte } \\
\text { da informação e a expressão do } \\
\text { próprio conteúdo asseverado. }\end{array}$ \\
\hline & Predicado encaixador & $\begin{array}{l}\text { Utilizar um verbo factivo indicativo de } \\
\text { opinião para organizar a predicação de } \\
\text { seu pensamento com a desinência de } \\
1^{\text {a }} \text { pessoa do plural. }\end{array}$ \\
\hline
\end{tabular}

3 Para a codificação das ocorrências, utilizou-se uma notação própria que particulariza cada trabalho acadêmico coletado (M1 a M10 para as monografias; D1 a D10 para as dissertações, e T1 a T10 para as teses), a parte analisada (I - Introdução; F Fundamentação Teórica; C - Conclusão), o número da ocorrência no trabalho (01, 02, 03, 04, 05...) e o número em relação ao total de ocorrências no corpus em ordem crescente pela verificação (01, 02, 03, 04, 05...); tal como no seguinte exemplo: [ocorrência 431: (T3.I.32)]. A ocorrência de número 431 foi verificada na terceira tese, no recorte da introdução e foi a trigésima segunda ocorrência encontrada nesta tese. 
v. 8 (esp.)

$112-129$

set.

2018

Quadro 02 - Análise integrada do uso da evidencialidade para alto comprometimento em D10.1.07

\begin{tabular}{|c|c|c|}
\hline \multicolumn{3}{|c|}{$\begin{array}{l}\text { ANÁLISE INTEGRADA DO USO DA EVIDENCIALIDADE } \\
\text { PARA ALTO COMPROMETIMENTO - OCORRÊNCIA D1O.I.07 }\end{array}$} \\
\hline \multicolumn{3}{|c|}{$\begin{array}{l}\text { (02) SUPONHO também que tais dificuldades se devam ao fato de atualmente no } \\
\text { Brasil um estudo acadêmico, [...], gozar de um baixo status perante a sociedade de } \\
\text { modo geral - aquela pressuposição de que vai gerar um produto que "ninguém lê", } \\
\text { a não ser alguns poucos pares na academia - o que faz com que alguns atores dêem, } \\
\text { de certa forma, pouca importância ao trabalho de pesquisa empreendido (pp. 7-8). } \\
\text { (D10.I.07) }\end{array}$} \\
\hline ASPECTO & MARCA EVIDENCIAL & ESTRATÉGIA \\
\hline $\begin{array}{l}\text { Pragmático- } \\
\text { discursivo }\end{array}$ & Alto comprometimento & $\begin{array}{l}\text { Sinalizar um pensamento de sua } \\
\text { responsabilidade exclusiva. }\end{array}$ \\
\hline \multirow[t]{3}{*}{ Semântico } & Sujeito-enunciador & $\begin{array}{l}\text { Atribuir a si próprio a fonte da } \\
\text { informação veiculada. }\end{array}$ \\
\hline & Menos direta & $\begin{array}{l}\text { Atestar que a informação foi um } \\
\text { constructo mental a partir da própria } \\
\text { mente do produtor textual. }\end{array}$ \\
\hline & Inferencial & $\begin{array}{l}\text { Explicitar que a informação foi } \\
\text { deduzida pela mente do próprio } \\
\text { produtor textual. }\end{array}$ \\
\hline \multirow[t]{2}{*}{ Sintático } & Intercalada & $\begin{array}{l}\text { Posicionar o evidencial entre a fonte } \\
\text { da informação e a expressão do } \\
\text { próprio conteúdo asseverado. }\end{array}$ \\
\hline & Predicado encaixador & $\begin{array}{l}\text { Utilizar um verbo factivo indicativo de } \\
\text { opinião para organizar a predicação de } \\
\text { seu pensamento com a desinência de } \\
1^{\text {a }} \text { pessoa do singular. }\end{array}$ \\
\hline
\end{tabular}

Nos exemplos (03) e (04) a seguir, observamos a utilização da estratégia discursiva de médio comprometimento com o informe dado. O produtor textual tem um pensamento sobre algo ou alguma coisa, mas ele não se compromete diretamente com esse pensamento, sendo que, para isso, usa algumas marcas apropriadas para atenuar a sua responsabilidade com o que informa, conforme os quadros abaixo: 
Quadro 03 - Análise integrada do uso da evidencialidade para médio comprometimento em T2.C.03

\begin{tabular}{|c|l|l|}
\hline \multicolumn{3}{|c|}{ ANÁLISE INTEGRADA DO USO DA EVIDENCIALIDADE } \\
PARA MÉDIO COMPROMETIMENTO - OCORRENCIA T2.C.03 \\
\hline $\begin{array}{l}\text { (03) EVIDENTEMENTE, uma ou outra coalizão de governo pode garantir uma } \\
\text { tramitação mais célere devido a compromissos políticos firmados com os atores } \\
\text { sociais e políticos interessados nas demarcaçôes (p. 266). (T2.C.03) }\end{array}$ \\
\hline \multicolumn{1}{|c|}{ ASPECTO } & MARCA EVIDENCIAL & \multicolumn{1}{c|}{ ESTRATÉGIA } \\
\hline $\begin{array}{l}\text { Pragmático- } \\
\text { discursivo }\end{array}$ & Médio comprometimento & $\begin{array}{l}\text { Sinalizar um pensamento que não é } \\
\text { de sua responsabilidade exclusiva. }\end{array}$ \\
\hline \multirow{5}{*}{ Semântico } & Sujeito-enunciador & $\begin{array}{l}\text { Atribuir a si próprio a fonte da } \\
\text { informação veiculada. }\end{array}$ \\
\cline { 2 - 3 } & Menos direta & $\begin{array}{l}\text { Atestar que a informação foi um } \\
\text { constructo mental a partir de sinais } \\
\text { contextuais. }\end{array}$ \\
\cline { 2 - 3 } & Inferencial & $\begin{array}{l}\text { Explicitar que a informação foi } \\
\text { deduzida pela mente do próprio } \\
\text { produtor textual. }\end{array}$ \\
\hline \multirow{2}{*}{ Sintático } & Anteposta & $\begin{array}{l}\text { Posicionar o evidencial antes da } \\
\text { Fonte da informação e da expressão } \\
\text { do conteúdo asseverado. }\end{array}$ \\
\cline { 2 - 3 } & Item adverbial & $\begin{array}{l}\text { Usar um advérbio que reforce a } \\
\text { certeza do produtor textual, mas de } \\
\text { forma atenuada. }\end{array}$ \\
\hline
\end{tabular}

Quadro 04 - Análise integrada do uso da evidencialidade para médio comprometimento em D8.I.02

\begin{tabular}{|c|l|l|}
\hline \multicolumn{3}{|c|}{ ANÁLISE INTEGRADA DO USO DA EVIDENCIALIDADE } \\
PARA MÉDIO COMPROMETIMENTO - OCORRÊNCIA D8.I.02
\end{tabular}


v. 8 (esp.)

$112-129$ set. 2018

O baixo comprometimento não é simples estratégia de total "irresponsabilidade" com a informação veiculada, pois, quando o produtor textual faz uso da citação de um estudioso acerca de uma pesquisa que é relevante para o seu estudo, ele estabelece um interrelacionamento com as ideias de tal pesquisador, tratando-se de um recurso usual para o chamado argumento de autoridade.

o produtor textual utiliza com maior frequência o nível de baixo comprometimento com o que ele está veiculando, mediante a utilização em larga escala das citações. Considero a citação como estratégia de baixo comprometimento, porque o produtor textual poderia apropriarse das ideias de um estudioso, transmitindo-as como se fossem suas, caso que ocorre com muita frequência quando se trata da constituição da intertextualidade ${ }^{4}$.

Nos quadros seguintes, mostramos a análise integrada da utilização da estratégia discursiva de baixo comprometimento com a informação veiculada:

Quadro 05 - Análise integrada do uso da evidencialidade para baixo comprometimento em T5.I.09

\begin{tabular}{|l|l|l|}
\hline \multicolumn{3}{|c|}{ ANÁLISE INTEGRADA DO USO DA EVIDENCIALIDADE } \\
PARA BAIXO COMPROMETIMENTO - OCORRENCIA T5.I.09 \\
\hline $\begin{array}{l}\text { (05) O veado-campeiro, Ozotoceros bezoarticus (Artiodactyla, Cervidae), é um cervídeo } \\
\text { de porte médio que foi, até um passado recente, amplamente distribuído na América } \\
\text { do Sul (EISENBERG \& REDFORD, 1999) (p. 11). (T5.I.09) }\end{array}$ \\
\hline ASPECTO & MARCA EVIDENCIAL & ESTRATÉGIA \\
\hline $\begin{array}{l}\text { Pragmático- } \\
\text { discursivo }\end{array}$ & Baixo comprometimento & $\begin{array}{l}\text { Sinalizar um pensamento que não é } \\
\text { de nenhuma responsabilidade sua. }\end{array}$ \\
\hline \multirow{5}{*}{ Semântico } & Fonte externa definida & $\begin{array}{l}\text { Atribuir a fonte da informação } \\
\text { veiculada a outra pessoa. }\end{array}$ \\
\cline { 2 - 3 } & Indireta & $\begin{array}{l}\text { Atestar que a informação foi } \\
\text { adquirida indiretamente. }\end{array}$ \\
\cline { 2 - 3 } & Relatada & $\begin{array}{l}\text { Explicitar que a informação tem } \\
\text { uma fonte específica e veiculada } \\
\text { no texto. }\end{array}$ \\
\hline Sintático & Posposta & $\begin{array}{l}\text { Posicionar o evidencial depois } \\
\text { da fonte da informação e a } \\
\text { expressão do próprio conteúdo } \\
\text { asseverado. }\end{array}$ \\
\cline { 2 - 3 } & Justaposição simples & $\begin{array}{l}\text { Utilizar a citação do argumento } \\
\text { de autoridade com a simples } \\
\text { identificação do autor justaposta } \\
\text { à própria citação. }\end{array}$ \\
\hline
\end{tabular}

${ }_{4}$ Esse termo designa ao mesmo tempo uma propriedade constitutiva de qualquer texto e o conjunto das relações explícitas ou implícitas que um texto ou um grupo de textos determinados mantêm com outros textos (CHARAUDEAU; MAINGUENEAU, 2004, p. 288). 
Quadro 06 - Análise integrada do uso da evidencialidade para baixo comprometimento em D2.F.14

\begin{tabular}{|c|l|l|}
\hline \multicolumn{3}{|c|}{ ANÁLISE INTEGRADA DO USO DA EVIDENCIALIDADE } \\
PARA BAIXO COMPROMETIMENTO - OCORREENCIA D2.F.14
\end{tabular}

Com base no corpus de 1.500 ocorrências organizado, projetamos

o quadro a seguir, que especifica a ocorrência da manifestação da evidencialidade nos trabalhos acadêmicos de grau em relação ao nível de comprometimento estabelecido pelo produtor textual5:

${ }^{5}$ Atribui-se a seguinte notação para o quadro em questão: $\mathrm{x}$ = baixa frequência (quando ocorrer menos de 10\%); $\mathrm{xx}=$ média frequência (quando ocorrer entre 10 e 40\%); $\mathrm{xxx}=$ alta frequência (quando ocorrer acima de 40\%). 
v. 8 (esp.)

$112-129$

set.

2018

Quadro 07. - Manifestação da evidencialidade em relação ao comprometimento

\begin{tabular}{|c|c|c|c|}
\hline \multicolumn{4}{|c|}{ NÍVEL DE COMPROMETIMENTO } \\
\hline MARCA EVIDENCIAL & $\begin{array}{c}\text { ALTO } \\
\text { COMPROMETIMENTO }\end{array}$ & $\begin{array}{c}\text { MÉDIO } \\
\text { COMPROMETIMENTO }\end{array}$ & $\begin{array}{c}\text { BAIXO } \\
\text { COMPROMETIMENTO }\end{array}$ \\
\hline Anteposta & - & - & XXX \\
\hline Intercalada & $\mathrm{X}$ & $\mathrm{XX}$ & $\mathrm{xXX}$ \\
\hline Posposta & $\mathrm{X}$ & $\mathrm{X}$ & $\mathrm{XXX}$ \\
\hline Verbal & $\mathrm{XX}$ & $\mathrm{xX}$ & $\mathrm{xXX}$ \\
\hline Substantiva & $\mathrm{X}$ & $\mathrm{X}$ & $\mathrm{X}$ \\
\hline Adjetiva & - & - & $\mathrm{xX}$ \\
\hline Prepositiva & - & - & $\mathrm{XX}$ \\
\hline Adverbial & - & $\mathrm{X}$ & - \\
\hline Sujeito-enunciador & $\mathrm{X}$ & $\mathrm{X}$ & - \\
\hline $\begin{array}{l}\text { Fonte externa } \\
\text { definida }\end{array}$ & - & - & xxx \\
\hline $\begin{array}{l}\text { Fonte externa } \\
\text { indefinida }\end{array}$ & - & - & $\mathrm{X}$ \\
\hline Domínio comum & - & $\mathrm{X}$ & $\mathrm{X}$ \\
\hline Subjetiva & $\mathrm{X}$ & $\mathrm{X}$ & $\mathrm{X}$ \\
\hline Experiencial & $\mathrm{X}$ & $\mathrm{X}$ & $\mathrm{X}$ \\
\hline Inferencial & $\mathrm{X}$ & $\mathrm{x}$ & $\mathrm{X}$ \\
\hline Relatada & - & - & $\mathrm{xxx}$ \\
\hline Direta & $\mathrm{X}$ & $\mathrm{X}$ & - \\
\hline Menos direta & - & $\mathrm{xX}$ & - \\
\hline Indireta & - & - & $\mathrm{xXX}$ \\
\hline $\begin{array}{l}\text { Item lexical ou } \\
\text { gramatical }\end{array}$ & $\mathrm{X}$ & $\mathrm{xX}$ & $\mathrm{xxx}$ \\
\hline $\begin{array}{l}\text { Enunciado } \\
\text { metadiscursivo }\end{array}$ & $\mathrm{x}$ & - & $\mathrm{x}$ \\
\hline Justaposição simples & - & - & $\mathrm{XX}$ \\
\hline Normas citativas & - & - & $\mathrm{XX}$ \\
\hline
\end{tabular}

De acordo com os dados do quadro 07 constatamos que:

a) quando o produtor textual quer manifestar ao leitor um alto comprometimento com as informações veiculadas, ele costuma utilizar as marcas evidenciais com as seguintes características: interposta ou posposta; verbal ou substantiva; sujeito-enunciador como fonte; natureza subjetiva, experiencial ou inferencial; acesso direto e enunciado metadiscursivo; 
b) quando o produtor textual quer manifestar no leitor um médio comprometimento com as informações dadas, ele busca esse efeito de sentido utilizando todas as marcas evidenciais referentes às seguintes características: interposta ou posposta; verbal, substantiva, adverbial; sujeitoenunciador ou de domínio comum; natureza subjetiva, experiencial ou inferencial; acesso direto ou menos direto;

c) quando o produtor textual quer manifestar no leitor um baixo comprometimento com as ideias relatadas, ele usa todas as marcas evidenciais que se caracterizam pelas seguintes propriedades: a posição no discurso (anteposta, interposta, posposta); a verbal, como predominante, substantiva, adjetiva, prepositiva; fonte externa definida ou fonte externa indefinida; natureza subjetiva, experiencial, inferencial, relatada; indireta; enunciado metadiscursivo, justposição simples, normas citativas da ABNT.

Os resultados obtidos explicitam a larga utilização da evidencialidade como estratégia de baixo comprometimento com as informações relatadas ${ }^{6}$ - apesar de que, quando alguém é citado, é possível supor que o produtor se compromete com a informação, com o referencial teórico etc. Isso se deve ao fato de que a citação é um recurso discursivo e convencionalmente utilizado na produção acadêmica.

Tal procedimento ocorre com essa frequência devido às orientações encontradas em manuais de metodologia científica, que sugerem uma postura impessoal do produtor textual com os conteúdos asseverados por ele, proporcionando uma atenuação da responsabilidade com o que está sendo dito.

Constatou-se que os efeitos de sentido associados ao uso de meios de expressão da evidencialidade na construção da argumentação dos textos acadêmicos de grau do português brasileiro contemporâneo colaboram para que essa atenuação da responsabilidade seja feita de forma discreta, sinalizando que algo não está sendo dito de forma categórica.

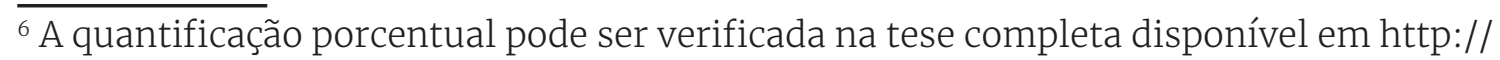
www.repositorio.ufc.br/handle/riufc/3608. 
v. 8 (esp.)

$112-129$

set.

2018

\section{Considerações finais}

A abordagem funcionalista foi extremamente importante para a efetivação deste trabalho, pois, o processo de construção textual envolve uma série de elementos linguísticos que, integrados numa análise, possibilitam uma avaliação eficaz do que se quer demonstrar com a pesquisa, como ocorre com a marca evidencial, que não pode ser vista de forma isolada, mas pela integração dos aspectos citados - expedientes sintáticos e semânticos - e do seu uso discursivo - expedientes pragmáticos -, pois a sua utilização depende da intencionalidade do produtor textual, como todos os outros recursos da língua.

O uso discursivo da evidencialidade foi aqui apresentado como uma estratégia para obtenção de um efeito de sentido a ser interpretado pelo leitor; logo, comoa evidencialidade tem por funçãoa indicação da fonte da informação, o produtor textual pode, intencionalmente, mostrar ou não essa fonte, de um modo ou de outro. Para isso, utiliza os níveis de comprometimento que a evidencialidade proporciona com seus variados recursos linguísticos.

\section{Referências}

ANDERSON, L. B. Evidentials, paths of change, and mental maps. In: CHAFE, W.; NICHOLS, J. (Eds.). Evidentiality: the linguistic coding of epistemology. Norwood, NJ: Ablex, 1986.

BAKHTIN, M. Estética da criação verbal. 2. ed. Tradução: Maria Ermantina Galvão G. Pereira. São Paulo: Martins Fontes, 1997. - (Coleção Ensino Superior).

BOTNE, R. Evidentiality and epistemic modality in lega. Studies in language, V. 2, n. 3, 1997.

BYBEE, J.; FLEISCHMAN, S. (Eds.). Modality in grammar and discourse. Amsterdam; Philadelphia: John Benjamins, 1995.

CARIOCA, C. R. A Evidencialidade nos textos acadêmicos de grau do português brasileiro contemporâneo. Fortaleza: EDUFC, 2011.

CHAFE, W.; NICHOLS, J. (Eds.). Evidentiality: the linguistic coding of epistemology. Norwood, NJ: Ablex, 1986.

CHARAUDEAU, P.; MAINGUENEAU, D. Dicionário de análise do discurso. Coord. Tradução: Fabiana Komesu. São Paulo: Contexto, 2004.

DALL'AGLIO HATTNHER, M. M. Uma Análise functional da modalidade epistêmica. Revista Alfa, n. 40, 1996.

DALL'AGLIO HATTNHER, M. M. et al. Uma investigação funcionalista da modalidade epistêmica. In: NEVES, M. H. de M. (Org.). Descrição do português: definindo rumos de pesquisa. Araraquara; São Paulo: FCL/UNESP; Cultura Acadêmica, 2001. (Série Trilhas Linguísticas, 1). 
DIK, C. S. The theory of functional grammar. Dordrecht: Foris Publications, 1989.

DENDALE, P.; TASMOWSKI, L. L'evidentialité ou le marquage dês sources du savoir. Langue Française, V. 102, 1994. Pragmatics, V. 33, 2001.

Introduction: evidentialy and related notions. Journal of

DU BOIS, J. The discourse basis of ergativity. Language, n. 63, 1987, p. 805855.

FLOYD, R. The structure of evidencial categories in wanka quechua. Dallas: Summer Institute of Linguistics, 1999.

GALVÃO, V. C. C. Evidencialidade e gramaticalização no português do Brasil: os usos da expressão diz que. 2001. 241f. Tese (Doutorado em Linguística e Língua Portuguesa) - Faculdade de Ciências e Letras, Universidade Estadual Paulista, Araraquara, 2001.

GIVÓN, T. Syntax: an introduction. Amsterdam; Philadelphia: J. Benjamins, 2001. (v. 1).

HALLIDAY, M. A. K. An introduction to functional grammar. 2. ed. London: Edward Arnold, 1994 [1985].

HENGEVELD, K. Layers and operators in functional grammar. Journal Linguistics, n. 25, 1989.

HOPPER, P.; THOMPSON, S. Transitivity in grammar and discourse. Language 56 (2): 251-299, 1980.

JAKOBSON, R. Shifters and verbal categories. Cambridge: Harvard University Press, 1990 [1957].

KOCH, I. G. V. Argumentação e linguagem. São Paulo: Cortez, 1986.

NEVES, M. H. de M. Texto e gramática. São Paulo: Contexto, 2006.

NOGUEIRA, M. T. Considerações sobre o funcionalismo linguístico: principais vertentes. In: SEMINÁRIO DO GRUPO DE ESTUDOS DISCURSO E GRAMÁTICA, 10., 2006, Natal. Anais... Natal: EDUFRN, 2006.

NUYTS, J. Epistemic modal adverbs and adjectives and the layered representation of conceptual and linguistic structure. Linguistics, v. 31, 1993.

Subjectivity as an evidential dimension in epistemic modal expressions. Journal of Pragmatics, v. 33, 2001.

THOMPSON, G. Introduction Functional Grammar. Londres: Arnold Publishers, 1996.

WILLETT, T. A cross-linguistic survey of the grammaticization of evidentiality. In.: Studies in Language, v. 1, n. 12, 1988. 